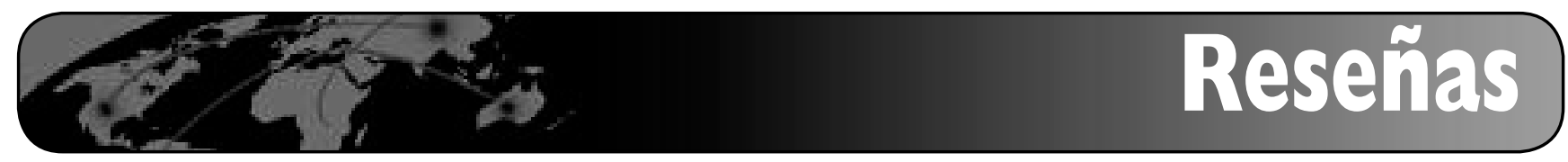

\title{
10as Jornadas españolas de documentación
}

\author{
Por Javier Leiva-Aguilera
}

Leiva-Aguilera, Javier. "10as Jornadas españolas de documentación”. En: El profesional de la información, 2007, septiembre-octubre, v. 16, n. 5, pp. 527-532.

DOI: 10.3145/epi.2007.sep.18

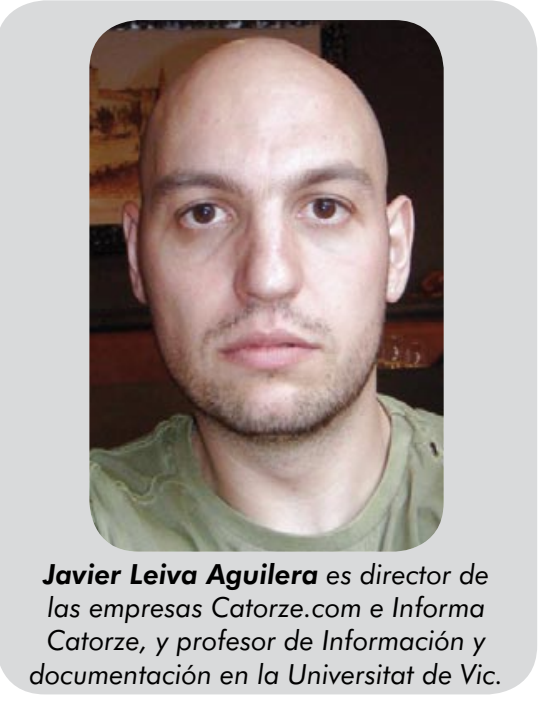

CON LA PRESENCIA DE MÁS DE 800 PROFESIONALES desplazados desde toda la geografía española, los pasados 9,10 y 11 de mayo de 2007 se celebraron en Santiago de Compostela las 10as Jornadas españolas de documentación, Fesabid 2007.

\section{http://www.fesabid.org/santia-} go2007/

En el espacio central del Palacio de Congresos, la feria Documat distribuía el espacio hacia las salas. En ella se dieron cita 46 empresas expositoras y fue el lugar donde se desarrollaron las pausa-café. Dado que era de obligado paso, se trataba de una zona idónea para el establecimiento de relaciones profesionales o comerciales, por lo que siempre se podían ver reuniones de toda índole más allá de las propias presentaciones de servicios o produc- tos. En otra área, la exhibición de pósters era bastante menos lucida por estar ubicada en un lateral lejos de las salas y con una iluminación deficiente. Seguramente en el espacio central de Documat hubieran quedado mucho mejor integrada.

\section{"Las Jornadas españolas de documentación contaron en su décima edición con la presencia de más de $\mathbf{8 0 0}$ profesionales"}

La conferencia inaugural corrió a cargo de José-Antonio Marina y llevaba por título Manual de instrucciones para sobrevivir al exceso de información. Una frase sugerente que cumplió las expectativas y una intervención en la que el filósofo quiso poner especial énfasis en la paradoja que existe en el mundo de nuestros días: mientras unos pocos millones de personas estamos saturados de información, la gran mayoría ni tan siquiera tiene acceso a ella.

Pero el programa científico como tal daba comienzo el jueves

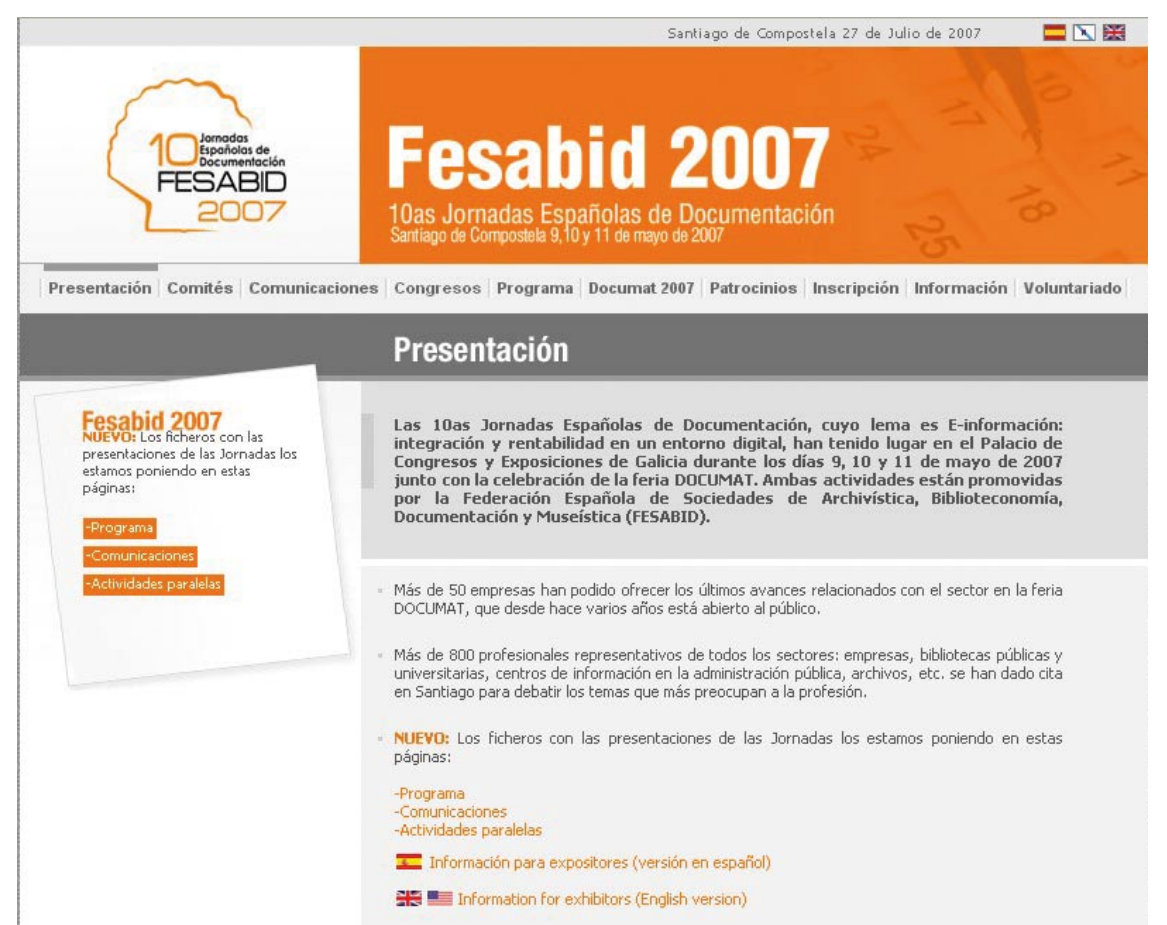

Página web de las 10as jornadas Españolas de Documentación 
por la mañana. Del mismo destacaremos básicamente cuatro propuestas por el enfoque novedoso de su temática.

\section{El futuro de los buscadores}

Isidro Aguillo moderó la mesa redonda El futuro de los buscadores: nuevas tendencias en recuperación de información, donde intervinieron Richard Benjamins, Eva Méndez, Antonio Pareja-Lora, José-Ramón Pérez-Agüiera y Antonio S. Valderrábanos. Fue un acto con gran confluencia de público, al igual que ocurrió en todos los relacionados con la tecnología y las nuevas herramientas, y se habló de buscadores horizontales y verticales y de cómo desde unos orígenes en que la recuperación de información en internet se realizaba a través de directorios se había evolucionado hacia el modelo de comenzar la navegación ante una caja de búsqueda vacía. También se habló de metadatos (Dublin Core, sobre todo), ontologías, procesamiento del lenguaje natural, algoritmos y semántica. La pena fue que la segunda parte de esta actividad coincidió en el tiempo con la celebración de la actividad paralela titulada Los blogs en la biblioteca 2.0: la blogosfera bibliotecaria, documentalista y archivera. Dado que había bastante público interesado en ambos actos, quien decidió acudir a éste último se perdió las últimas 3 intervenciones.

En todo caso, los que se quedaron pudieron escuchar una interesante charla de Antonio Pareja-Lora, que explicó conceptos básicos sobre web semántica, ontologías y SKOS (simple knowledge organisation system), que es una propuesta de representación estandarizada del World Wide Web Consortium (W3C) para sistemas de organización del conocimiento. José-Ramón Pérez-Agüera, por su parte, habló de recuperación de información y de web semántica

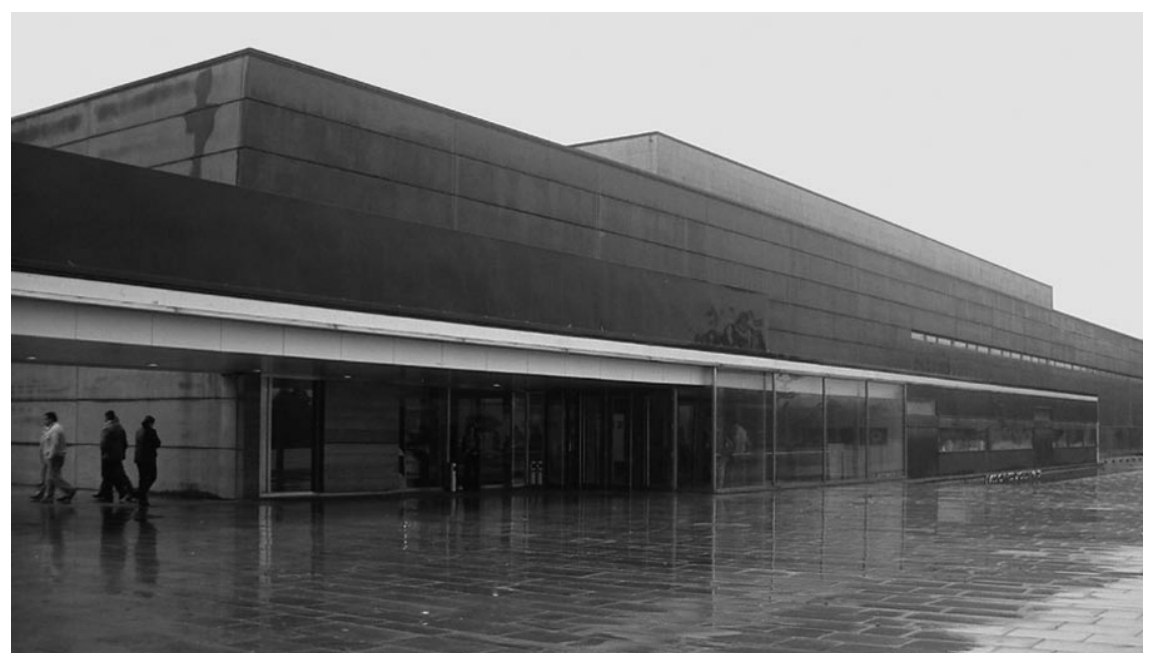

Palacio de Congresos de Santiago

exponiendo los problemas a los que se enfrentan los buscadores actualmente (integrar correctamente información lingüística de modo que no sólo comprendan, sino también usen para afinar los resultados) y proponiendo algunas soluciones:

- Integración de la información lingüística en el índice.

- Reformulación de las funciones de ponderación y ranking para que no trabajen sobre la asunción de independencia de términos.

Finalmente Antonio S. Valderrábanos comparó el modo de gestionar información hasta hace unos años (analógicamente) y cómo ese sistema se ha vuelto inviable hoy en día a causa de la explosión de la información gracias a los formatos electrónicos. Afortunadamente han aparecido los buscadores automáticos, que cada vez son capaces de gestionar cantidades más grandes de datos y al mismo tiempo ofrecer mejores resultados en la recuperación.

\section{Blogs e internet 2.0}

Volvemos a la actividad de blogs, que se celebró en una sala totalmente llena (en general, como ya se ha apuntado, las actividades ligadas a las últimas tendencias tecnológicas se ubicaron en salas demasiado pequeñas en relación con el interés que despertaron). Participaron dos asociaciones con blog
(Asnabi y Sedic), dos bibliotecarios (Catuxa Seoane y Marcos Ros), un profesor que los utiliza como elemento de integración (Jorge Franganillo) y un bibliotecario sin blog pero que está sacando mucho partido a las nuevas herramientas de la llamada internet 2.0 aplicándolas a la biblioteca de Muskiz: Fernando Juárez. El moderador de la sesión fue José-Antonio Merlo-Vega.

\section{"Las actividades ligadas a las últimas tendencias tecnológicas despertaron mucho interés y las salas se quedaron pequeñas"}

Los representantes de las dos asociaciones (Asunción Maestro y Elisa Prieto) explicaron sus experiencias en relación con el formato tratado. El blog de Asnabi está muy centrado en el territorio navarro y en la problemática relacionada con los profesionales y las bibliotecas. Se trata, muchas veces, de un blog reivindicativo y a través del cual la Asociación quiere hacer oir su voz ante la sociedad y la administración de Navarra. En todo caso para ellos ha supuesto también una herramienta excelente para establecer vínculos más allá de las fronteras políticas $\mathrm{y}$, por lo tanto, enriquecer- 
se a través del contacto con profesionales de toda España.

El caso de Sedic es un poco distinto: en su papel de asociación nacional no puede circunscribirse a una comunidad en concreto, y por otro lado la intención en el momento de crear el blog no era tanto dar salida a la información de la propia asociación sino dinamizar a los asociados. En ese contexto, convocaron a cualquiera que pudiera estar interesado en generar contenidos y crearon un consejo de redacción que funciona como un grupo de trabajo. De este modo se escribe sobre temas relacionados con la biblioteconomía y la documentación pero pocas veces sobre la propia asociación, que tiene otros canales de difusión.

\section{http://asnabi.blogspirit.com/}

http://blog.sedic.es/

El siguiente en intervenir fue Marcos Ros, del blog El documentalista enredado junto a MaríaElena Mateo. Habló de los inicios del blog como simple soporte a un proyecto más grande: un portal integrador de contenidos sobre la profesión. Finalmente, el portal desapareció y el blog tomó todo el protagonismo. El ponente destacó cómo este formato permite al autor comunicar contenido que conoce, pero al mismo tiempo le obliga a aprender otro nuevo con el que seguir alimentando su publicación. Por otro lado, la interacción con el lector lo convierte en una excelente herramienta de autoaprendizaje.

http://www.documentalistaenredado.net/

Por su parte, Catuxa Seoane habló de Deakialli, que mantiene junto a la también documentalista Vanesa Barrero. Fue uno de los primeros sobre el tema escritos en castellano y comenzó como soporte a una práctica realizada durante los estudios en la universidad. Con el tiempo fue evolucionando y ha dado como resultado una gran di-

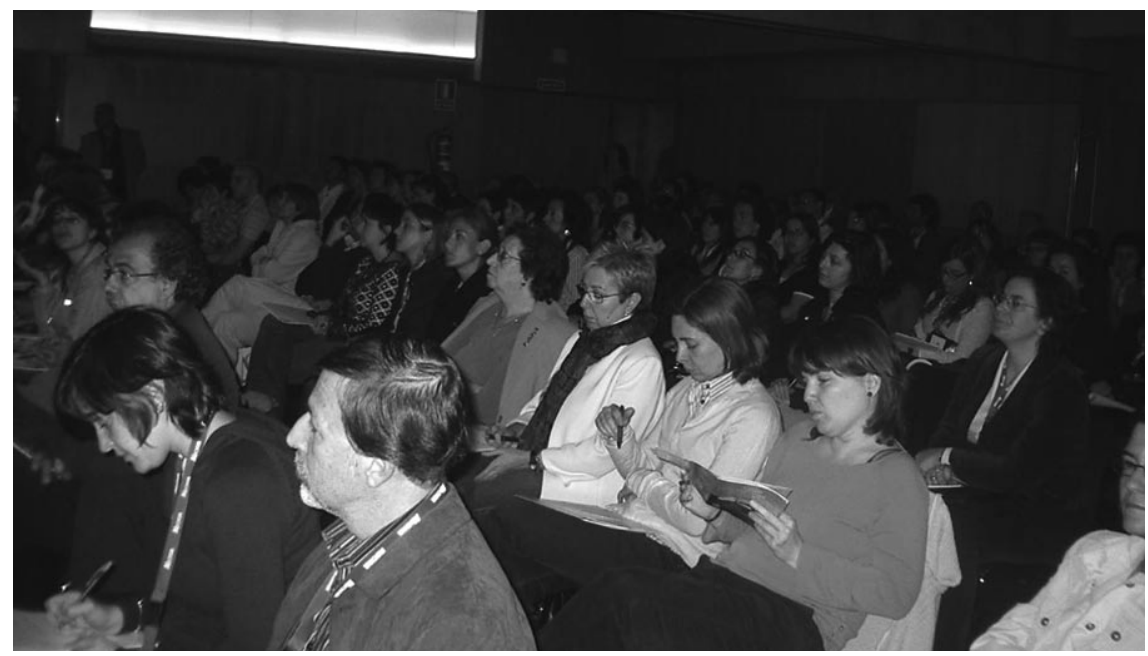

Público en la sesión de blogs

versidad de contenidos, ofreciendo a las autoras una serie de contactos profesionales que quizá no hubieran conseguido sin su uso. Seoane se centró en ese tema, el del blog como herramienta de marketing personal y como centralizador de la información visible en internet sobre una persona.

\section{http://www.deakialli.com/}

A partir de este momento, el tono de las intervenciones cambió porque ya no se trataba de personas que quisieran relatar sus propias experiencias con blogs sino alrededor de ellos. Jorge Franganillo presentó una experiencia de alfabetización digital en un centro de menores a través de los blogs. Destacó entre otras cosas que el hecho de que los internos tuvieran de repente una ventana desde donde expresarse para el mundo entero les había hecho reflexionar sobre sus ideas y la manera de expresarlas. En resumen, también ellos habían visto en los blogs una herramienta para crear marca personal.

El último en intervenir fue Fernando Juárez, de la biblioteca de Muskiz. Juárez no dispone de blog pero sí hace uso de ellos y de otras tecnologías de las llamadas 2.0 para mejorar el servicio que ofrece su biblioteca a los usuarios. En concreto, ha convertido la web de la biblioteca en un mashup donde se combinan distintas herramientas y dan lugar a un servicio donde se puede consultar un mapa literario, suscribirse a los hilos de redifusión de las novedades de distintas bibliotecas, hablar en tiempo real con el personal del centro, etc. El discurso de Juárez se centró en mostrar cómo sin apenas recursos y sólo con ganas de mejorar y de dedicar un poco de tiempo a aprender algunas herramientas cualquiera puede convertir una página web estática en un centro de recursos de gran utilidad para el usuario. Esta última aportación tuvo mucha relación con el tema que se trataba en otra actividad paralela: Biblioteca 2.0: ¿el futuro de los opac?

http://www.muskiz-liburutegia. org/

Después de las intervenciones el espacio abierto al público estuvo muy animado y se pudo profundizar en algunas de las ideas expresadas. Por otro lado, se lamentó la oportunidad perdida por la organización del congreso al oponerse a poner en marcha un blog dedicado al conjunto de las Jornadas aprovechando que se celebraba un actividad paralela sobre el tema.

\section{Rentabilidad de la información}

La mesa redonda Rentabilidad de la información se desarrolló en la jornada del jueves, en sesión de tarde, y moderada por Remedios 


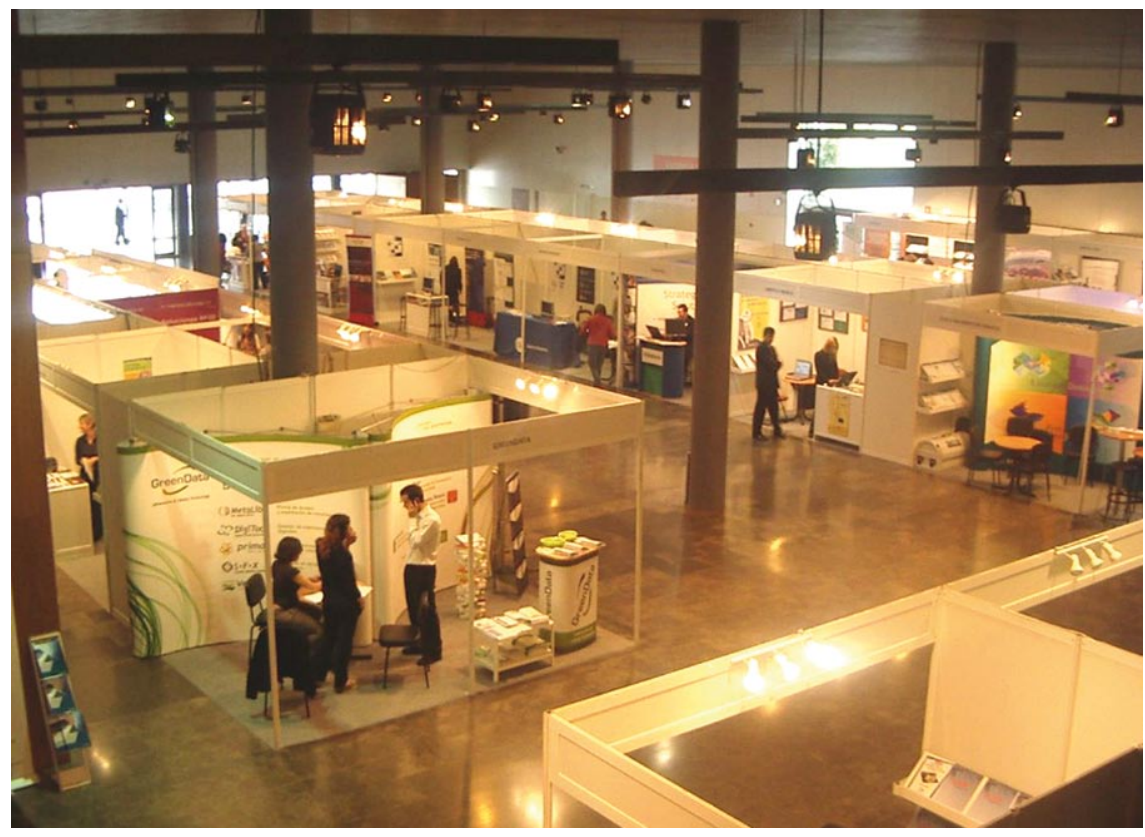

Aspecto de Documat

Melero y Tomàs Baiget. Precisamente los moderadores abrieron la sesión con una presentación donde empezaban diferenciando entre valor absoluto y dinámico de la información. Es éste último valor el que importa cuando se habla del tema que ocupaba la mesa redonda, puesto que la información se ve sometida a un proceso en el que intervienen los documentalistas y al que es posible calcular los costes y, por lo tanto, el retorno sobre la inversión. La presentación continuaba hablando de las múltiples implicaciones de la rentabilidad del recurso "información" y cómo no se puede recurrir únicamente a aspectos cuantitativos para valorar su rentabilidad: es necesario tener en cuenta el valor que se le otorga de antemano y la calidad que tiene (intrínseca o no).

Joaquín León-Marín, de la biblioteca de la Universidad de La Rioja, intentó demostrar cómo un proyecto desarrollado por bibliotecarios desde el sector público (Dialnet) puede ser rentable social y económicamente.

León definió este servicio como un portal integrador de recursos y servicios de información orientado a las bibliotecas y al usuario final.
Enfocado al tema de la rentabilidad de la información, argumentó que se trata de un proyecto cooperativo que permite evitar duplicidades en las tareas y centralizar esfuerzos y productos. Para demostrar los resultados positivos de la experiencia, el ponente presentó algunos indicadores cuantitativos así como los resultados de las encuestas de evaluación realizadas entre los usuarios del portal.

\section{http://dialnet.unirioja.es/}

Por su parte, el documentalista-periodista de Cinco días Guillermo Montesinos habló del tema desde un enfoque eminentemente económico en el que habló de la gran cantidad de información presente en internet pero no accesible gratuitamente o que sí lo está pero dificilmente encontrable. En lo que respecta al primer caso, habló de los tradicionales proveedores de información electrónica (Thomson, Reuters, etc.). Por otro lado, también hizo referencia al hecho de que no es igual decir información gratis que información sin coste. De otro modo, serían imposibles los desembolsos millonarios que empresas como Google vienen haciendo regularmente para adquirir a otras que ofrecen todo el contenido gra- tuitamente a sus usuarios (Youtube, etc.). En estos casos, simplemente, el valor se calcula de otra forma.

El último en intervenir fue Daniel Román-Ramentol, de la Universitat Oberta de Catalunya, quien habló de la importancia de medir la rentabilidad de la información para poder mejorarla, en concreto mediante la identificación de una selección adecuada de soluciones y de su puesta en práctica.

Román ofreció seis enfoques para medir la esta rentabilidad:

- Mediante una cifra.

- A través del volumen económico del sector que generan los proveedores de soluciones de rentabilidad.

- Gracias al volumen económico del sector de los que ayudan a implantar soluciones de rentabilidad.

- Tomando como ejemplos las empresas de mayor crecimiento.

- Mediante el nivel de riqueza de los directivos o fundadores de empresas que ofrecen soluciones de rentabilidad.

- Analizando los costes de la no rentabilidad.

\section{Open Access Initiative}

El viernes por la mañana tuvo lugar la actividad titulada Presente y futuro del OAI en España, que estaba organizada por Fernanda Peset y Cristina de la Peña.

En primer lugar intervino Karen Spence, de la Osti (Office for Scientific and Technical Information, de EUA) bajo el título Acelerando la difusión del conocimiento para el avance de la ciencia y la tecnología hizo una descripción de las tareas que viene realizando su institución desde el año 1947. Su misión se podría resumir en dos puntos (recoger/preservar y dar acceso) y la conclusión a la que han llegado después de todos estos años 
es que si se acelera la compartición de conocimiento se desarrolla también el progreso científico. Por lo tanto, Spence es una firme defensora de los archivos abiertos.

\section{http://www.osti.gov/}

El siguiente en intervenir fue Juan Corrales, que explicó la experiencia de un consorcio puesto en marcha con la intención de crear una plataforma de soporte al proceso de la comunicación científica en acceso abierto en el mundo digital: el Consorcio Madroño. Corrales explicó las características principales de la plataforma así como sus especificaciones técnicas y terminó exponiendo los proyectos de futuro: ampliar el número de instituciones participantes, colaborar en la evolución hacia una red nacional española de acceso abierto y dotar al proyecto de un impulso internacional (principalmente en América Latina). net/

http://www.consorciomadrono.

Seguidamente se desarrolló una mesa redonda moderada por Tomàs Baiget donde el representante de la Fecyt, José-Manuel Báez-Cristóbal, empezó hablando de la Becyt (Biblioteca Electrónica de Ciencia y Tecnología) y seguidamente pasó al terreno de los archivos abiertos y describió el papel de su institución como aglutinador de experiencias en el ámbito científico español. En ese sentido, defendió la concentración de iniciativas como modo de focalizar los recursos y así conseguir menos dispersión y más calidad. Más tarde, se produjo una situación algo contradictoria cuando la representante del Ministerio de Cultura, María-Isabel CuadradoFernández, dijo que el Ministerio iba a lanzar una nueva convocatoria de proyectos abierta a todos.

Por otro lado, intervinieron Manuela Palafox (Universidad Complutense de Madrid), Santiago Baos (Invenia), Gema Bueno

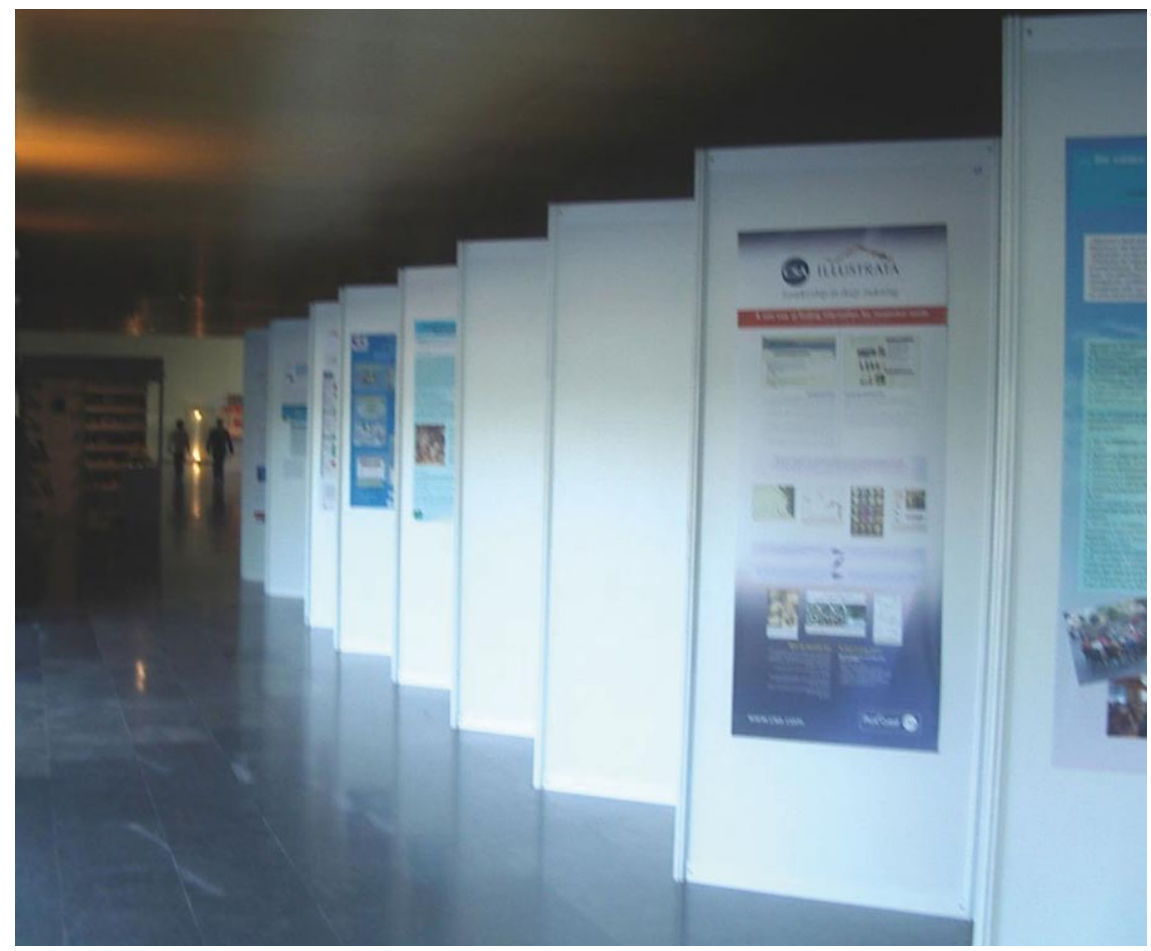

Espacio de posters en Fesabid 2007

(Universidad Carlos III) y JoséManuel Barrueco (Universidad de Valencia). Cada uno de ellos expuso los trabajos de su institución con relación a este tema, y quizá podemos destacar la defensa de E-Lis realizada por Barrueco, argumentada sobre la base de la importancia que toman las comunidades de expertos que se forman a su alrededor, y la de Gema Bueno, que insistió en la función de los repositorios como memoria de la institución, medida de su eficacia y carta de presentación ante la comunidad científica.

\section{http://eprints.rclis.org/}

En la discusión final se planteó la disyuntiva, según unos, o la complementariedad según la mayoría, de los repositorios institucionales y de los temáticos. Cada tipo tiene sus propias funciones y áreas de influencia, y los aspectos positivos de los institucionales (recopilación directa de trabajos que quizá nunca serían depositados y se perderían, ayuda a la toma de conciencia sobre la importancia de archivar y conservar...) seguramente superan la enorme duplicación de medios (especialmente técnicos) y la dis- persión física. Esto último debería poder resolverse satisfactoriamente con la aplicación de las normas OAI-PMH y con los buscadores generales como Google.

\section{Otras propuestas}

Dentro del programa de las jornadas había también otras sesiones que, si bien no son tratadas individualmente en este resumen, no carecen de interés.

En lo que respecta a las sesiones de comunicaciones, estuvieron estructuradas en tres epígrafes:

- Información y ciudadanía.

- Información y Red.

- Innovación.

El resto de mesas redondas y actividades paralelas tenían que ver con la tecnología, el ámbito universitario, la gestión documental y de archivos y la normativización, la propiedad intelectual, la conservación, la deontología y la alfabetización internacional. Los títulos (y algunas presentaciones en ppt o pdf) pueden hallarse en el programa de las Jornadas (ver nota al final). 
"Mientras unos pocos millones de personas estamos saturados de información, la gran mayoría ni tan siquiera tiene acceso a ella"

Complementariamente a la programación del congreso, se celebraron en el mismo recinto dos eventos paralelos:

- $I^{a}$ Jornada de software libre para servicios y unidades de información.

- La biblioteca digital europea: una apuesta por la multiculturalidad.

Aunque no estaban faltos de interés, la opinión generalizada era que se les asignó un espacio muy apartado del resto y su celebración era practicamente invisible para los asistentes. A causa de esto, buena parte de las sesiones estaban practicamente vacías (algo que se acentuó por el hecho de que se programaron en una sala enorme).
La conferencia de clausura corrió a cargo de Julie McLeod y trató sobre la normalización en relación con el desarrollo profesional de los que trabajan en información y documentación. Pero la clausura final, la que de verdad cerraba las jornadas, se celebró comiendo (como debe ser) en el Pazo de San Lorenzo.

\section{Conclusiones}

Las Jornadas Españolas de Documentación siempre son una buena ocasión para que los profesionales dejen por unos días el aislamiento de su puesto de trabajo y se reencuentren con antiguos compañeros, conozcan nuevos productos y métodos de trabajo, presenten su trabajo al resto, intercambien opiniones, etc. También para que los estudiantes tomen un primer contacto con la comunidad profesional en la que están a punto de entrar. En ese sentido, esta edición no ha sido distinta de las anteriores.

Por otro lado, y pese a que no siempre las salas asignadas a las actividades han sido las adecuadas visto el interés despertado por cada una de ellas, el recinto era excelente y el marco de celebración (Santiago de Compostela) inmejorable.
En cuanto al contenido, hay que destacar el esfuerzo por presentar una oferta innovadora en vez de seguir en los títulos de siempre. El sector de la información y la documentación y todo lo que lo rodea evoluciona a gran velocidad y era necesario que las jornadas más importantes del sector en nuestro territorio reflejaran esa realidad.

Ahora sólo nos queda esperar a las próximas, que serán en 2009 en Zaragoza. ¡Allí nos vemos!

\section{Notas}

Montesinos-Ballesteros, Guillermo. Examen al valor de la documentación digital. Consultado en: 27 julio 2007.

http://www.cincodias.com/articulo/empresas/ Examen/valor/documentacion/digital/cdscdi/ 20070518cdscdiemp_20/Tes/

Peset, Fernanda. Fesabid 2007: actividad sobre OAI. Consultado en: 27 julio 2007.

http://listserv.rediris.es/cgi-bin/wa? $A 2=i n d 0705$ $c \& L=$ iwetel $\& D=1 \& P=2361$

Programa de las 10as Jornadas Españolas de Documentación. Consultado en: 27 julio 2007. http://www.fesabid.org/santiago2007/programa. php

Javier Leiva-Aguilera, Catorze. com.

javier@catorze.com

\section{Próximos temas centrales}

Noviembre 2007
Enero 2008
Marzo 2008
Mayo 2008
Julio 2008
Septiembre 2008
Noviembre 2008

Noviembre 2007

Ontologías

Software libre para bibliotecas

Inovación en bibliotecas públicas

Presente y futuro de la profesión

Libros electrónicos

Información en la empresa

Redes sociales

Los interesados pueden remitir notas, artículos, propuestas, publicidad, comentarios, etc., sobre estos temas a:

epi@elprofesionaldelainformacion.com 


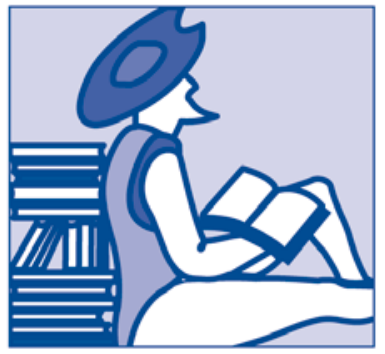

F U N ACI Ó N Alonso Quijano

\section{¿qué hacemos?}

Fomento de la lectura con menores hospitalizados.

Actividades de Formación.

Revista Mi Biblioteca.

Cooperación Internacional.

Recursos sobre lectura en la web.

\section{¿quieres colaborar?}

Hazte socio/a y recibirás estos dos libros de regalo*.

Cuota mínima: $20 €$ al año.
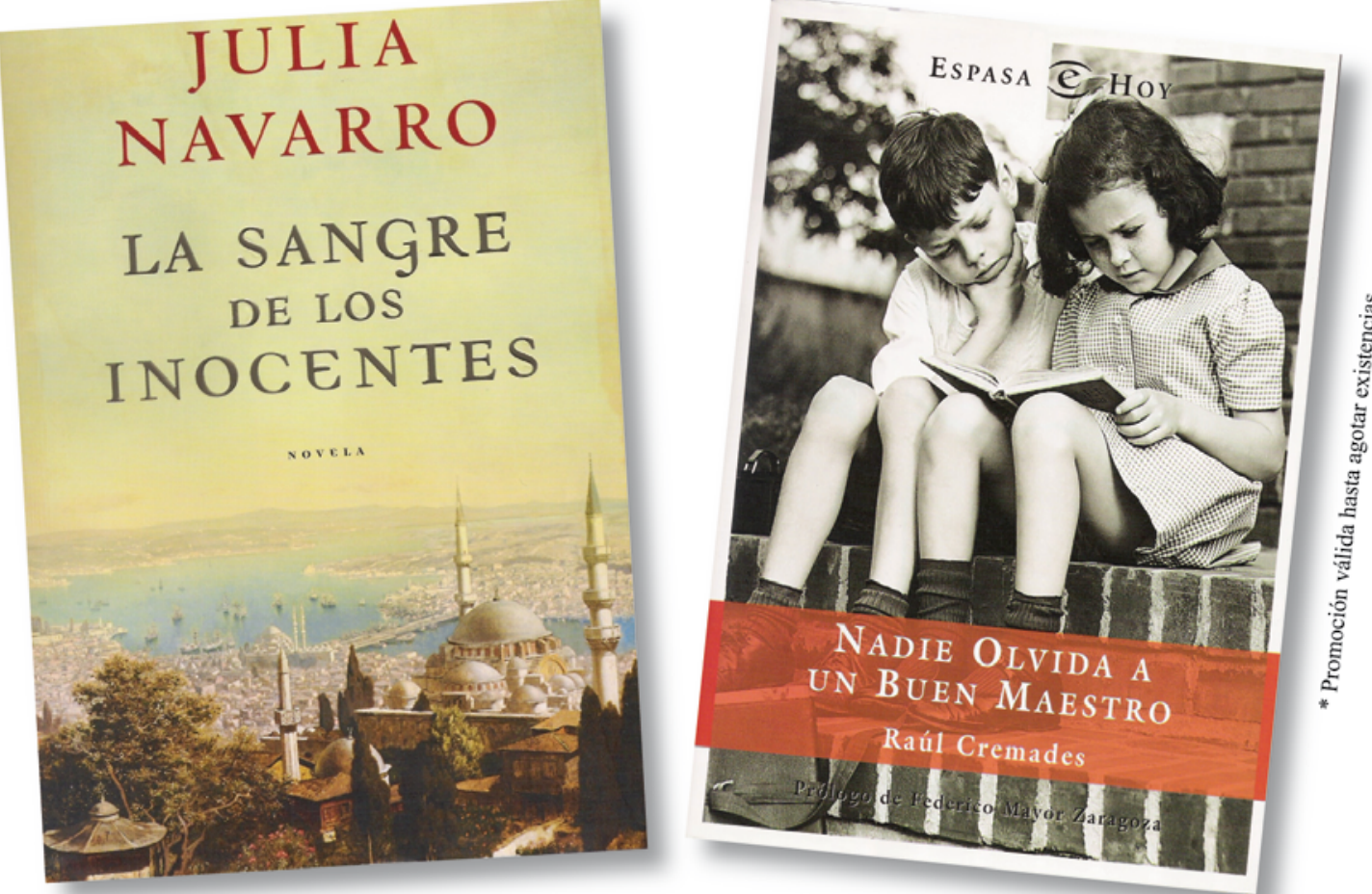

Puedes hacerlo por teléfono: 902362869 - 952235405 o a través de nuestra web: www.alonsoquijano.org

\section{Asóciate y disfruta de estas ventajas:}

- Regalo de un libro cada año como agradecimiento por la colaboración con la Fundación.

- Información sobre las actividades de la Fundación y participación en sorteos y promociones.

- Descuentos en suscripciones a revistas del sector.
- Descuentos en los cursos y otras actividades de formación organizadas por la Fundación.

- Regalo del Calendario de la Lectura que la Fundación publica cada año.

- Ventajas fiscales según la legislación vigente sobre mecenazgo. 